\title{
Evaluation of Care Quality Related to Dietary Intake and Swallowing Functions of Residents at Long-Term Facilities in Japan
}

\author{
Sayuri Kaneko \\ Department of Nursing Administration, Miyagi University, Miyagi, Japan \\ Email: kanekos@myu.ac.jp
}

How to cite this paper: Kaneko, S. (2021) Evaluation of Care Quality Related to Dietary Intake and Swallowing Functions of Residents at Long-Term Facilities in Japan. Open Journal of Nursing, 11, 610-619. https://doi.org/10.4236/ojn.2021.117052

Received: June 2, 2021

Accepted: July 20, 2021

Published: July 23, 2021

Copyright $\odot 2021$ by author(s) and Scientific Research Publishing Inc. This work is licensed under the Creative Commons Attribution International License (CC BY 4.0).

http://creativecommons.org/licenses/by/4.0/

\begin{abstract}
This study aimed to evaluate the quality of healthcare services pertaining to the dietary intake and swallowing functions of residents, nutrition management practices, and performance of residents at long-term care facilities. We investigated outcome indicators, such as changes in dietary intake and swallowing function levels of residents, and clarified which structural and process indicators were associated with the outcome indicators. This was a retrospective study, analyzing information on healthcare services from 1067 long-term care facilities during the fiscal year 2012, sampled from among those registered with the Welfare, Health and Medical Care Information Network of the Welfare and Medical Service Agency in Japan. Five outcome indicators were identified. Next, we examined the relationships between the outcome indicators and structural or process indicators using a multivariate linear regression model, adjusting for facility type. The findings showed how the five outcome indicators were used in long-term care facilities over a period of one year and determined the independent predictors of these outcome indicators. The amplification of dietary function 1 was associated with "assessment of oral functions using a feeding and swallowing assessment checklist every three months", "holding care conferences related to ingestion and swallowing every three months", and "maintaining a 1:2 ratio for meal-time assistants to residents". To improve the quality of care, it is necessary to increase the number of staff (e.g., to provide meal assistance to residents) and to understand changes in the residents' status through accurate assessment and monitoring.
\end{abstract}

\section{Keywords}

Dietary Intake, Long-Term Care Facility, Nutrient Intake, Quality Indicators, Swallowing Functions 


\section{Introduction}

The quality of care in long-term care facilities (LTCFs) is gaining attention in developed countries with a rapidly aging population [1] [2]. In Japan, although the supply of care has increased since the long-term care insurance system was enforced in 2000, problems related to the quality of care have become apparent; therefore, safe and high-quality care needs to be provided in long-term care. Providing safe and high-quality care services anytime and anywhere is a top-priority policy issue, and to make it happen, a mechanism for quality evaluation and improvement of care services is necessary. Evaluation of care quality needs to be examined from three perspectives: structure, process, and outcome [3]. In other countries, various attempts have been made to evaluate the quality of care using this framework. Evaluating how outcome indicators are affected by structural and process indicators can indicate how the provision of high-quality care can be improved. Based on this proposal, we validate details of the quality of care in LTCFs in Japan, such as infection control, medication management, and care management, to maintain and improve activities of daily living and cognitive functions [4] [5] [6].

This study focused on the dietary intake and swallowing function of residents in LTCFs, since many residents have eating dysfunctions. The prevalence of dysphagia in residents of LTCFs is reported to be around $45.3 \%$ to $59.7 \%$ in Japan [7] and $40 \%$ to $60 \%$ in Europe and the United States [8]. Considering the age of the residents in LTCFs, where $64.4 \%$ were 85 years old or older, the risk of aspiration pneumonia has been shown to be high [9]. In addition, if the dietary intake is reduced because of temporary deterioration of masticatory function, health issues such as malnutrition and sarcopenia may follow, and a vicious cycle such as further dysphagia occurs [10].

In LTCFs, dietary care is provided by devising a dietary plan that considers ingestion dysfunction [11] [12]. In addition, it has been reported that in some facilities, the undernutrition status of residents was improved by appropriately evaluating the feeding function of residents and carefully devising nutritional care plans [13]. However, in many LTCFs, it is difficult to evaluate eating and swallowing functions in collaboration with medical institutions, using swallowing contrast examination and swallowing endoscopy. Screening eating and swallowing functions using a simple evaluation sheet without other adjacent evaluations have not been sufficiently tested [14]. To improve the oral intake of residents, an appropriate evaluation of eating and swallowing, along with effective nutritional care management is indispensable.

This study focuses on the dietary intake and swallowing functions of residents in LTCFs and investigates the evaluation of care quality from the aspects of structure, process, and outcome. The aims of this study were to investigate (1) outcome indicators, such as changes in dietary intake and swallowing functions of residents in LTCFs, and (2) the factors affecting outcome indicators through structural and process indicators of care providers and care systems. Under- 
standing the causes of these outcomes and the factors contributing to these outcomes is essential since more information can lead to an improvement in safety and quality of the healthcare system in LTCFs.

\section{Methods}

\subsection{Setting}

This research employed a retrospective study design. The sample consisted of welfare facilities, healthcare facilities, and medical care facilities for older adults, as defined by the long-term care insurance system in Japan. Welfare facilities are facilities that provide care for older adults who cannot receive appropriate care at home, given that they will permanently require care as a result of significant physical or mental decline. In contrast, healthcare facilities are facilities that provide the care necessary for residents to return home, such as medical care and rehabilitation following acute care. Finally, medical care facilities for older adults are facilities that provide the necessary medical care after acute care.

Of the 6920 LTCFs registered in the Welfare, Health, and Medical Care Information Network of the Welfare and Medical Service Agency, only 1402 provided consent to participate, after which questionnaires were administered to the nurse managers or facility officers of the facilities.

\subsection{Data Collection}

We collected information on healthcare services at the facilities from April 2012 to March 2013. The questionnaire was composed of three parts: structure, process, and outcome indicators according to Donabedian's framework [3]. This survey was originally created to reflect the care management of LTCFs in Japan, such as the activity and cognitive function of residents, intake and nutrition management, infection control, and medication management. The questionnaire has a total of 120 items, of which the items related to intake and nutritional management were as follows: The 12 structural indicators included facility organization, personnel allocation, and characteristics of the standard care system in the facility. The process indicators comprised 18 items that included the frequency risk assessment, the conference enforcement situation, and implementation of patient safety strategies, such as analyzing ingestion and swallowing accidents or conducting training. The outcome indicators were five items that included the occurrence of ingestion and swallowing accidents, problems during tube feeding and care after gastrostomy, and the ratio of residents whose feeding improved in the facility during 2012. The definitions and calculation formulas for the outcome indicators are listed in Table 1.

\subsection{Data Analysis}

Five outcomes were evaluated in this study. The five outcomes for each facility type were compared using the chi-square test and Mann-Whitney $U$ test. Multivariate linear regression models were developed through a stepwise selection 
Table 1. Occurrence of outcome indicators.

\begin{tabular}{|c|c|c|c|}
\hline & Outcome indicators & Definition & $\begin{array}{l}\text { Calculating formula }= \\
\text { numerator/denominator }\end{array}$ \\
\hline 1 & $\begin{array}{l}\text { Amplification of the } \\
\text { meal intake function } 1\end{array}$ & $\begin{array}{l}\text { Ratio of residents whose } \\
\text { feeding was improved from } \\
\text { "tube feeding only" to "tube } \\
\text { feeding with oral feeding" per } \\
100 \text { residents concerned }\end{array}$ & $\begin{array}{l}=\text { Number of residents who } \\
\text { can take even one bite by tube } \\
\text { feeding from tube feeding } \\
\text { only/Total number of } \\
\text { residents requiring tube } \\
\text { feeding } \times 100\end{array}$ \\
\hline 2 & $\begin{array}{l}\text { Amplification of the } \\
\text { meal intake function } 2\end{array}$ & $\begin{array}{l}\text { Ratio of residents whose } \\
\text { feeding was improved from } \\
\text { "requiring full meal-time } \\
\text { assistance" to "partial } \\
\text { meal-time assistance" per } \\
100 \text { residents concerned }\end{array}$ & $\begin{array}{l}=\text { Number of residents } \\
\text { improved from requiring full } \\
\text { assistance to partial assistance } \\
\text { at meal-time/Total number of } \\
\text { residents requiring meal-time } \\
\text { assistance } \times 100\end{array}$ \\
\hline 3 & $\begin{array}{l}\text { Amplification of the } \\
\text { meal intake function } 3\end{array}$ & $\begin{array}{l}\text { Ratio of residents whose } \\
\text { feeding was improved from } \\
\text { "requiring partial meal-time } \\
\text { assistance requirement" to } \\
\text { "meal-time attention" per } \\
100 \text { residents concerned }\end{array}$ & $\begin{array}{l}=\text { Number of residents } \\
\text { improved from requiring } \\
\text { partial assistance to attention } \\
\text { at meal-time/Total number of } \\
\text { residents requiring meal-time } \\
\text { assistance } \times 100\end{array}$ \\
\hline 4 & $\begin{array}{l}\text { Occurrence of } \\
\text { ingestion and } \\
\text { swallowing } \\
\text { accidents }\end{array}$ & $\begin{array}{l}\text { Number of accidental cases } \\
\text { about ingestion and swallowing } \\
\text { per } 1000 \text { residents concerned } \\
\text { during one year }\end{array}$ & $\begin{array}{l}=\text { Number of accidental } \\
\text { cases about ingestion and } \\
\text { swallowing/Total number of } \\
\text { residents who is able to take } \\
\text { oral } \times 1000\end{array}$ \\
\hline 5 & $\begin{array}{l}\text { Occurrence of problems } \\
\text { with tube feeding and } \\
\text { after gastrostomy }\end{array}$ & $\begin{array}{l}\text { Number of trouble cases about } \\
\text { tube feeding and after } \\
\text { gastrostomy per } 1000 \text { residents } \\
\text { concerned during one year }\end{array}$ & $\begin{array}{l}=\text { Number of trouble cases } \\
\text { about tube feeding and after } \\
\text { gastrostomy/Total number of } \\
\text { residents requiring tube } \\
\text { feeding and } \\
\text { gastrostomy } \times 1000\end{array}$ \\
\hline
\end{tabular}

method to examine the relationship between each of the five outcomes with 12 structural indicators and 18 process indicators. The influence of facility factors was analyzed after the statistical adjustment of the facility type. The analyses were performed using SPSS for Windows, version 24.0 J (IBM, Japan), with the level of significance set at $\mathrm{p}<0.05$.

\subsection{Ethics Approval}

This study was approved by the ethics committee of the Graduate School of Nursing of Nagoya City University (12024-2). Survey respondents were provided a written explanation of the study's purpose and were informed that participation was voluntary and that the confidentiality of their personal information would be protected. These procedures are in line with the Declaration of Helsinki (as revised in Brazil). Returning the questionnaire was considered as their consent to participate in this study. 


\section{Results}

\subsection{Characteristics of Participating Facilities and Residents}

Questionnaires were returned by 1402 facilities, and the response rate was $20.3 \%$. Among them, 1067 facilities with a description of seven outcome indicators were considered to have provided valid responses in this study, constituting $76.1 \%$ of the total responses. Of these, 541 (50.7\%) were welfare facilities, 324 (30.4\%) were healthcare facilities, and 202 (18.9\%) were medical care facilities for older adults. Table 2 shows the characteristics of the participating facilities.

The average number of residents per facility was 75.3 , and their average age was 87.8 . Women comprised $74.3 \%$ of the residents. Facility residents were classified according to the level of care they required, using the five categories laid out by the long-term care insurance system in Japan. On average, $4.2 \%$ of facility residents were Level 1 residents, who required partial care for some aspects of activities of daily living; $16.4 \%$ were Level 2 residents, who required a low level of care; $24.2 \%$ were Level 3 residents, who required a moderate level of care; $26.8 \%$ were Level 4 residents, who required a high level of care, and $28.4 \%$ were Level 5 residents, who required the highest level of care.

\subsection{Occurrence of Outcome Indicators}

The ratio of amplification of meal intake function 1 was $8.4 \%$ in welfare facilities, $12.4 \%$ in healthcare facilities, and $5.2 \%$ in medical care facilities for older adults, while the ratios of amplification of meal intake function 2 were $3.0 \%$, $8.1 \%$, and $5.8 \%$, respectively. The ratios of amplification of meal intake function 3 were $2.5 \%, 6.7 \%$, and $5.6 \%$, respectively. The incidence rates of accidental ingestion and swallowing per facility type were 11.0 (per 1000 residents of concern in one year), 7.1, and 10.1, respectively. The incidence rates of problems during tube feeding and the after gastrostomy per facility type were 9.9, 10.1, and 10.3, respectively. No significant differences were found between the five outcome indicators for any of the three facilities.

Table 2. Characteristics of participating long-term care facilities $(\mathrm{N}=1067)$.

\begin{tabular}{llc}
\hline & & $\mathrm{n}(\%)$ \\
\hline Number of residents & $<50$ & $190(17.8)$ \\
& $50-100$ & $547(51.3)$ \\
Location & $100<$ & $330(30.9)$ \\
\multirow{2}{*}{ Funding type } & Rural & $570(53.4)$ \\
& Urban & $497(46.6)$ \\
Facility type & Private & $912(85.5)$ \\
& Public & $155(14.5)$ \\
& Welfare facility for the elderly & $541(50.7)$ \\
& Healthcare facility for the elderly & $324(30.4)$ \\
& Medical care facility for the elderly & $202(18.9)$ \\
\hline
\end{tabular}




\subsection{Performance of Structure and Process Indicators in LTCFs}

Table 3 shows the data for LTCFs, reporting the human resources in the facility and patient safety level of the standard care system. In all three types of facilities, the average number of residents per care staff member during the day was 2.3 and the average number of residents per nurse during the day was 12.1.

Table 3. Performance of structural and process indicators in long-term care facilities.

\begin{tabular}{|c|c|c|}
\hline \multicolumn{2}{|c|}{ Structural indicators } & \multirow{2}{*}{$\begin{array}{r}\text { Median (min-max) } \\
80.0(15.0-250.0)\end{array}$} \\
\hline 1 & Number of residents in facility & \\
\hline 2 & Rate of capacity utilization & $98.0(88.0-106.2)$ \\
\hline \multicolumn{3}{|c|}{ Level of care required for residents in facility } \\
\hline 3 & Rate of level 1 & $3.8(0.0-38.2)$ \\
\hline 4 & Rate of level 2 & $10.9(0.0-59.3)$ \\
\hline 5 & Rate of level 3 & $22.0(1.7-64.0)$ \\
\hline 6 & Rate of level 4 & $30.0(5.9-60.3)$ \\
\hline 7 & Rate of level 5 & $28.8(3.4-80.0)$ \\
\hline \multicolumn{3}{|c|}{ Human resources } \\
\hline 1 & Number of residents per doctor & $98.0(4.6-1860.0)$ \\
\hline 2 & Number of residents per nurse & $12.1(2.7-145.0)$ \\
\hline 3 & Number of residents per care staff & $2.3(1.0-56.0)$ \\
\hline 4 & Number of residents per speech therapist & $50.7(3.8-500.0)$ \\
\hline 5 & Number of residents per managerial dietician & $60.0(6.0-235.0)$ \\
\hline \multicolumn{2}{|c|}{ Process indicators } & $\mathrm{n}(\%)$ \\
\hline 1 & Revision of manuals for measures against nutritional care management per year & $712(82.3)$ \\
\hline 2 & $\begin{array}{l}\text { Increasing awareness of actions and improving measures against nutritional care } \\
\text { management among staff every three months }\end{array}$ & $546(63.1)$ \\
\hline 3 & $\begin{array}{l}\text { Holding review meetings and seminars related to measures against nutritional care } \\
\text { management every three months }\end{array}$ & $448(51.8)$ \\
\hline 4 & Assessment of oral functions using a feeding and swallowing assessment checklist every three months & $298(34.5)$ \\
\hline 5 & Holding care conferences related to ingestion and swallowing every three months & $577(66.7)$ \\
\hline 6 & Taking turns for risk identification such as danger on site every three months & $430(49.7)$ \\
\hline 7 & Understanding fluid input-output as well as food intake daily & $488(56.4)$ \\
\hline 8 & Weighing of patients daily & $845(97.7)$ \\
\hline 9 & Maintaining the 1:2 ratio of meal-time assistants to residents & $394(45.5)$ \\
\hline 10 & Considering autonomy devices specific for individual disabilities & $772(89.2)$ \\
\hline 11 & Convincing residents to leave their bed and go to a public place at meal-time & $852(98.5)$ \\
\hline 12 & Strictly prohibiting food consumption before hand/finger cleansing & $741(85.7)$ \\
\hline 13 & Use of different oral care products depending on oral condition & $767(88.7)$ \\
\hline 14 & Providing support for individual oral care (e.g., brushing) after every meal & $726(83.9)$ \\
\hline 15 & Providing oral care to residents requiring daily tube feeding & $783(90.5)$ \\
\hline 16 & Keeping the gastrointestinal site clean with running warm water and weakly alkaline soap & $462(53.4)$ \\
\hline 17 & Summarizing and statistically analyzing concerning incidents once a month & $628(72.6)$ \\
\hline 18 & Analysis of background factors at time of accident once a month & $688(79.5)$ \\
\hline
\end{tabular}


In more than $80 \%$ of facilities, the following eight process indicators were present: revision of manuals for measures against nutritional care management per year; weighing of patients; convincing residents to leave their bed and go to a public place (e.g., dining room) at meal-time; strictly prohibiting food consumption before hand/finger cleansing; considering autonomy devices specific for individual disabilities; use of different oral care products depending on oral condition; providing support for individual oral care (e.g., brushing) after every meal; and providing oral care to residents requiring daily tube feeding.

In contrast, $50 \%$ to $80 \%$ of the facilities performed the following seven process indicators: summarizing and statistically analyzing concerning incidents once a month; analysis of background factors at the time of an accident once a month; increasing awareness of actions and improving measures against nutritional care management among staff members every three months; holding review meetings and seminars related to measures of nutritional care management every three months; holding care conferences related to ingestion and swallowing every three months; understanding fluid input-output as well as food intake daily; and keeping the gastrointestinal site clean with running warm water and weakly alkaline soap.

Finally, less than $50 \%$ of facilities used these three process indicators: taking turns for risk identification such as danger on site every three months; assessment of oral functions using a feeding and swallowing assessment checklist every three months; and keeping the 1:2 ratio for the ratio of meal-time assistants to residents.

\subsection{Assessing Facility-Related Factors of Each Outcome Indicator}

As a result of the multiple regression analysis after adjusting for facility type in each of the five outcome indicators, related factors were shown for the amplification of the meal intake function 1 (Table 4). The amplification of meal intake function 1 showed a relationship with "assessment of oral functions using a feeding and swallowing assessment checklist every three months" $(\beta=0.14, \mathrm{p}<$ $0.05)$, "holding care conferences related to ingestion and swallowing every three months" $(\beta=0.10, \mathrm{p}<0.05)$ and "maintaining the $1: 2$ ratio for meal-time

Table 4. Factors associated with outcome indicators in long-term care facilities.

\begin{tabular}{lcc}
\hline \multicolumn{1}{c}{ The amplification of meal intake function 1 } & $\beta$ & $\mathrm{p}$ \\
\hline $\begin{array}{l}\text { Assessment of oral functions using a feeding and swallowing } \\
\text { assessment checklist every three months }\end{array}$ & 0.14 & $<0.05$ \\
Holding care conferences related to ingestion and & 0.10 & $<0.05$ \\
swallowing every three months & 0.08 & $<0.05$ \\
Maintaining the 1:2 ratio for meal-time assistants to residents & 0.14 \\
$\mathrm{R}^{2}$ & 1067 \\
$\mathrm{n}$ & & 106 \\
\hline
\end{tabular}

Note: $R^{2}, \beta$, standardized coefficients in multiple linear regression analysis using stepwise selection methods adjusted for facility types. 
assistants to residents" $(\beta=0.08, \mathrm{p}<0.05)$. There were no relationships between the other outcome indicators and the structural or process indicators.

\section{Discussion}

This study focused on the dietary intake and swallowing functions of residents in LTCFs and verified the quality evaluation of care from the aspects of structure, process, and outcome, advancing knowledge in two important aspects. First, the study showed how LTCFs use key outcome indicators over a period of one year. Second, the study determined the independent predictors of the outcome indicator: the amplification of the meal intake function 1 by structure and process indicators of care providers and care system in LTCFs.

\subsection{Outcome Indicators on the Dietary Intake and Swallowing Functions of Residents}

This study showed how LTCFs use key outcome indicators. In previous studies, the incidence of aspiration in LTCFs was unknown because it was difficult to confirm a medical diagnosis. It has been reported that aspiration pneumonia accounts for $80.1 \%$ in patients aged 85 years or older in general hospitals [15]. In addition, the prevalence of dysphagia among residents of facilities has been reported to be around $45.7 \%$ - 40.7\% [7]. However, there are no clear indicators of improved dietary intake or swallowing function levels. In this study, the incidence of aspiration and the rate of expansion of oral intake in residents was shown, and from the viewpoint of improving the quality of care related to diet and nutritional management, we were able to provide fundamental reference indicators.

\subsection{Affecting Facilities Factors of Each Outcome Indicator}

The study was able to determine the independent predictors of the outcome indicator, the structural and process indicators of the LTCF care system, out of five outcome indicators. The outcome, the amplification of dietary function 1, was associated with "Assessment of oral functions using a feeding and swallowing assessment checklist every three months", "holding care conferences related to ingestion and swallowing every three months", and "maintaining a 1:2 ratio of meal-time assistants to residents". Various efforts are being made to improve the quality of care regarding changes in the awareness of staff working at LTCFs, such as preparing manuals for nutrition management and study sessions [14] [16]. However, with regard to the current state of diet and nutrition care, less than half of the LTCFs did not conduct "evaluation of oral function using the eating and swallowing evaluation table" and "care conferences on eating and swallowing". This study showed that higher the frequency of "assessment of oral functions using a feeding and swallowing assessment checklist every three months" and "holding care conferences related to ingestion and swallowing every three month", higher is the ratio of residents whose feeding was improved 
from "tube feeding only" to "tube feeding with oral feeding" per 100 residents concerned. Therefore, it is important to understand the effects of care provided in facilities through accurate assessment and monitoring. In addition, there was a relationship between staffing and the number of staff at the time of meal assistance; therefore, in order to improve the quality of care related to meals and nutritional management in LTCFs, it is necessary to consider an increase in the number of staff members.

For the remaining four outcome indicators, there were no associations between structural and process indicators. This could be because of the effect of care that was not captured by the process indicators surveyed in this study. For example, in this survey, process indicators are primarily visualizations of care provision by care staff and nurses, and do not reflect the involvement of other professionals. In other words, regarding the involvement of professionals, only the number of professionals such as dentists and speech therapists is considered, and the extent to which professionals intervene in actual care is unknown. In addition, in order to promote the independence of food intake by facility residents, it is thought that the food preferences of residents are also related, but this point could not be verified by the survey. In the future, it will be necessary to visualize the details of the care delivery process of the facility and to reexamine the relationship with the outcome indicators.

In conclusion, this study focused on the dietary intake and swallowing functions of residents in LTCFs, showing the trends in the five outcome indicators in a period of one year, and determined the independent predictors of outcome indicators. To improve the quality of care related to meals and nutritional management in LTCFs, it is necessary to increase the number of staff who provide direct care, such as meal assistance to residents, and to understand changes in the state of residents through accurate assessment and monitoring. However, this result was analyzed based on the data from about 10 years ago, and it is necessary to continue the survey and grasp the secular change in care provision at the facility.

\section{Acknowledgements}

We thank the managers of the LTCFs who kindly opened the doors for this study, as well as encouraging the care staff. This study was supported by the Japan Society for the Promotion of Science KAKENHI (grant number 24390124).

\section{Disclosure Statement}

The author declares no conflict of interest.

\section{References}

[1] OECD (2005) Long-Term Care for Older People. The OECD Health Project. OECD Publishing, Paris.

[2] Colombo, F., Llena-Nozal, A., Mercier, J. and Tjadens, F. (2011) Help Wanted? 
Providing and Paying for Long-Term Care. OECD Health Policy Studies, OECD Publishing, Paris. https://doi.org/10.1787/9789264097759-en

[3] Donabedian, A. (2005) Evaluating the Quality of Medical Care. The Milbank Quarterly, 83, 691-729. https://doi.org/10.1111/j.1468-0009.2005.00397.x

[4] Kaneko, S. (2016) Infection Control and Prevention Factors Affecting Outbreaks of Influenza and Acute Viral Gastroenteritis in Long-Term Care Facilities in Japan. Journal of Applied Medical Sciences, 5, 45-55. http://www.scienpress.com/Upload/JAMS/Vol\%205_2_5.pdf

[5] Kaneko, S. and Okada, M. (2018) Medication Management Factors Associated with Medication Errors at Japanese Long-Term Care Facilities. Journal of Applied Medical Sciences, 7, 1-10.

[6] Kaneko, S. (2020) Safety and Quality of Care Evaluation in Japanese Long-Term Facilities Focused on the Activity Condition and Cognitive Function of Residents. Open Journal of Nursing, 10, 131-142. https://doi.org/10.4236/ojn.2020.102008

[7] Saito, E. (2010) Distribution and Severity Survey of Patients with Dysphagia Using the Clinical Severity Classification of Dysphagia "Survey and Research Project Report on Dysphagia”. National Center for Geriatrics and Gerontology, 9-10.

[8] Teramoto, S., Fukuchi, Y., Sasaki, H., Sato, K., Sekizawa, K. and Matsuse, T. (2008) High Incidence of Aspiration Pneumonia in Community- and Hospital-Acquired Pneumonia in Hospitalized Patients: A Multicenter, Prospective Study in Japan. Journal of American Geriatrics Society, 56, 577-579.

https://doi.org/10.1111/j.1532-5415.2008.01597.x

[9] Japanese Nursing Association (2016) Japanese Nursing Association Medical Policy Department: Nursing Staff Survey Report at Special Nursing Homes and Long-Term Care Health Facility.

[10] Kikutani, T. and Furuya, H. (2016) Oral Frailty as an Obstacle to Eating. Journal of the Japan Geriatrics Society, 53, 341-346.

[11] Wright, L., Cotter, D., Hickson, M. and Frost, G. (2005) Comparison of Energy and Protein Intakes of Older People Consuming a Texture Modified Diet with a Normal Hospital Diet. Journal of Human Nutrition and Diet, 18, 213-219. https://doi.org/10.1111/j.1365-277X.2005.00605.x

[12] Uemura, T. (2007) Survey of Eating and Swallowing Disorders and Food Support Status at Long-Term Care Health Facility. Journal of Japan Society for Dysphagia Rehabilitation, 11, 60-66.

[13] Kikutani, T. (2008) Nourishment Support in the Nursing Care Facility for the Elderly: Through Implemented Conference for Feeding Support. Japanese Journal of Gerontolog, 22, 371-376.

[14] Miyamoto, K., Goda, T., Sugiyama, M. and Koyama, H. (2010) The Presence of Dysphagia Screening Systems in View of Dysphagia Care Management. Journal of Japan Society for Healthcare Administration, 7, 145-153.

[15] Park, Y.H., Han, H.R., Oh, B.M., Lee, J., Park, J.A., Yu, S.J. and Chang, H. (2013) Prevalence and Associated Factors of Dysphagia in Nursing Home Residents. Geriatric Nursing, 34, 212-217. https://doi.org/10.1016/j.gerinurse.2013.02.014

[16] Kikutani, T., Enomoto, R., Tamura, F., Oyaizu, K., Suzuki, A. and Inaba, S. (2006) Effects of Oral Functional Training for Nutritional Improvement in Japanese Older People Requiring Long-Term Care. Gerodontology, 23, 93-98.

https://doi.org/10.1111/j.1741-2358.2006.00104.x 